Research Article

\title{
Heat Capacity and Thermodynamic Property of Cesium Tetraborate Pentahydrate
}

\author{
Kangrui Sun, Kaiyu Zhao, Long Li, Yafei Guo ${ }^{(D)}$, and Tianlong Deng \\ Tianjin Key Laboratory of Marine Resources and Chemistry, College of Chemical Engineering and Materials Science, \\ Tianjin University of Science and Technology, Tianjin 300457, China
}

Correspondence should be addressed to Yafei Guo; guoyafei@tust.edu.cn and Tianlong Deng; tldeng@tust.edu.cn

Received 4 January 2019; Accepted 6 February 2019; Published 26 February 2019

Academic Editor: João Paulo Leal

Copyright (c) 2019 Kangrui Sun et al. This is an open access article distributed under the Creative Commons Attribution License, which permits unrestricted use, distribution, and reproduction in any medium, provided the original work is properly cited.

\begin{abstract}
In order to recover cesium tetraborate pentahydrate $\left(\mathrm{Cs}_{2} \mathrm{O} \cdot 2 \mathrm{~B}_{2} \mathrm{O}_{3} \cdot 5 \mathrm{H}_{2} \mathrm{O}\right)$ from the high concentration cesium-containing salt lake brines and geothermal water resources, the molar heat capacity of $\mathrm{Cs}_{2} \mathrm{O} \cdot 2 \mathrm{~B}_{2} \mathrm{O}_{3} \cdot 5 \mathrm{H}_{2} \mathrm{O}$ has been measured with a precision calorimeter at the temperature from 303 to $349 \mathrm{~K}$. It was found that there is no phase transition and thermal anomalies. The molar heat capacity of cesium tetraborate pentahydrate is fitted as $\mathrm{C}_{\mathrm{p}, \mathrm{m}}\left(\mathrm{J} \cdot \mathrm{mol}^{-1} \cdot \mathrm{K}^{-1}\right)=593.85705+48.0694\left[T-\left(T_{\max }+T_{\min }\right) / 2\right] /$ $\left.\left(T_{\max }-T_{\min }\right) / 2\right]+24.86395\left[\left(T-\left(T_{\max }+T_{\min }\right) / 2\right) /\left(T_{\max }-T_{\min }\right) / 2\right]^{2}+0.53077\left[\left(T-\left(T_{\max }+T_{\min }\right) / 2\right) /\left(T_{\max }-T_{\min }\right) / 2\right]^{3}$, and the relevant thermodynamic functions of enthalpy, entropy, and Gibbs free energy of cesium tetraborate pentahydrate are also obtained at intervals of $2 \mathrm{~K}$ from 303 to $349 \mathrm{~K}$.
\end{abstract}

\section{Introduction}

The demands for cesium and its compounds have been sharply increased for their excellent properties and crucially commercial values in recent years [1]. Cesium ion with the biggest hydration in the periodic table determines its prominent properties and applications, such as large solubility and weak hydration in alkali borates. In addition, cesium compounds are applied in many modern high-tech fields owing to tremendous actinochemistry and excellent photoelectrical effect, and cesium borates also serve as the basic materials in new hybrid nonlinear optical materials [2]. Cesium resources were distributed and dispersed in the crust, associated with other minerals [3]; hence, the study of thermodynamic properties for cesium borates was necessary for synthesizing materials and extracting cesium borates from salt lake brines.

Heat capacity is a significant parameter to study the chemical engineering thermodynamics, which reflects the ability of matter to absorb or release heat without phase change [4], and it is beneficial to optimize the process route and improve the separation technology. There have been reported on the standard molar enthalpy of formation as well as the thermodynamic properties of aqueous solutions of $\mathrm{Cs}_{2} \mathrm{O} \cdot 2 \mathrm{~B}_{2} \mathrm{O}_{3} \cdot 5 \mathrm{H}_{2} \mathrm{O}$ with the group contribution method [5]. Sun [2] also accurately determined its density, electrical conductivity, and $\mathrm{pH}$ at 298.15 and $333.15 \mathrm{~K}$. The crystal structure of $\mathrm{Cs}_{2} \mathrm{O} \cdot 2 \mathrm{~B}_{2} \mathrm{O}_{3} \cdot 5 \mathrm{H}_{2} \mathrm{O}$ has been analyzed from single-crystal X-ray diffraction [6]. Zhang et al. [7] measured the molar heat capacity of aqueous $\mathrm{Li}_{2} \mathrm{~B}_{4} \mathrm{O}_{7}$ solution with a precision automated adiabatic calorimeter from 80 to $356 \mathrm{~K}$, and the heat capacity of lithium pentaborate pentahydrate has been reported previously in the range from 297 to $375 \mathrm{~K}$ using the SETARAM BT 2.15 adiabatic calorimeter [8]. However, there is no report on the molar heat capacity of solid minerals of $\mathrm{Cs}_{2} \mathrm{~B}_{4} \mathrm{O}_{7} \cdot 5 \mathrm{H}_{2} \mathrm{O}$ in the literature till now.

In this paper, in order to make full use of $\mathrm{Cs}_{2} \mathrm{O} \cdot 2 \mathrm{~B}_{2} \mathrm{O}_{3} \cdot 5 \mathrm{H}_{2} \mathrm{O}$ as well as its potential value, the heat capacity of cesium tetraborate pentahydrate was measured in the range 303 to $349 \mathrm{~K}$, and the relevant thermodynamic functions of enthalpy, entropy, and Gibbs free energy were also carried out for the first time. 


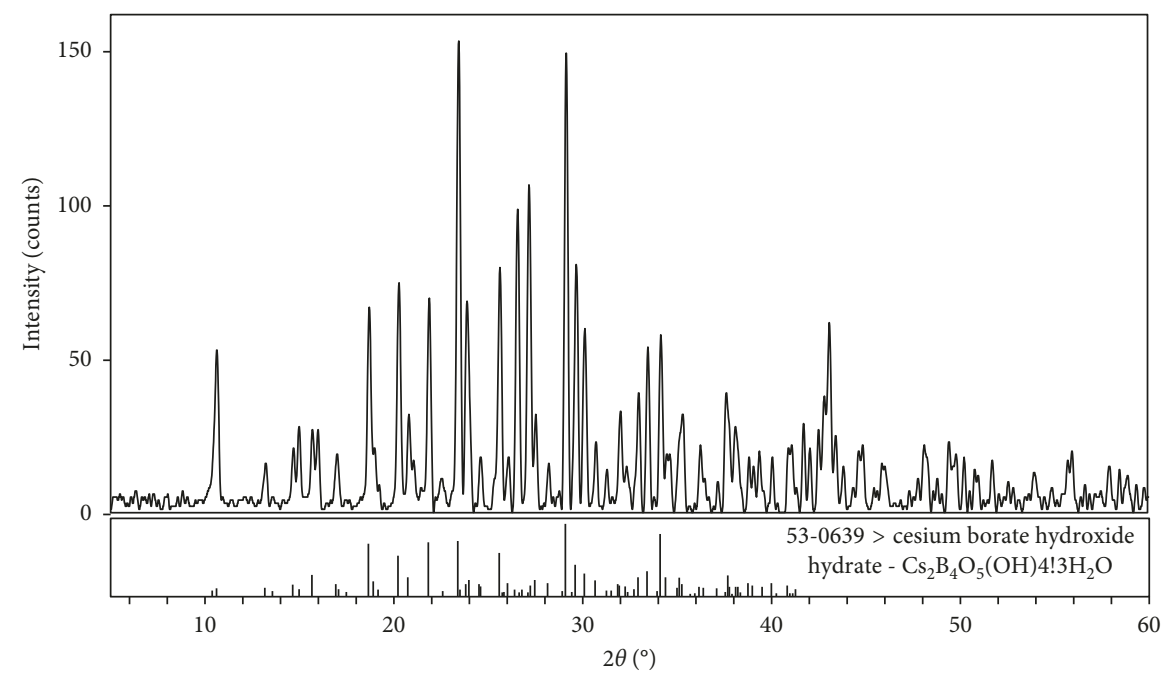

FIgure 1: The X-ray diffraction pattern of $\mathrm{Cs}_{2} \mathrm{O} \cdot 2 \mathrm{~B}_{2} \mathrm{O}_{3} \cdot 5 \mathrm{H}_{2} \mathrm{O}$.

\section{Experimental}

2.1. Synthesis of $\mathrm{Cs}_{2} \mathrm{~B}_{4} \mathrm{O}_{7} \cdot 5 \mathrm{H}_{2} \mathrm{O}$. The compound of $\mathrm{Cs}_{2} \mathrm{O} \cdot 2 \mathrm{~B}_{2} \mathrm{O}_{3} \cdot 5 \mathrm{H}_{2} \mathrm{O}$ was synthesized according to the literature [9]. Briefly, a certain amount of $\mathrm{H}_{3} \mathrm{BO}_{3}, \mathrm{Cs}_{2} \mathrm{CO}_{3}$, and deionized distilled water (DDW) was added accurately in a beaker, and then heated at $323.15 \mathrm{~K}$ and stirred for at least more than $30 \mathrm{~min}$ at $150 \mathrm{rpm}$ until dissolved completely. Then, the solution was filtered in an attemperator, and the clear solution was crystallized in a thermostat water bath at $303 \mathrm{~K}$. Finally, the solid phase was separated after washing three times with DDW and absolute ethyl alcohol separately, and then dried in a desiccator before use.

2.2. Identification and Analytical Methods of $\mathrm{Cs}_{2} \mathrm{O} \cdot 2 \mathrm{~B}_{2} \mathrm{O}_{3} \cdot 5 \mathrm{H}_{2} \mathrm{O}$. The power X-ray diffraction pattern of the synthesized compound in Figure 1 was obtained by using a PERSEE XD-3 polycrystalline X-ray diffractometer with $\mathrm{Cu}-\mathrm{K} \alpha$ radiation at $4 \mathrm{~min}^{-1}$, which corresponds to $\mathrm{Cs}_{2} \mathrm{O} \cdot 2 \mathrm{~B}_{2} \mathrm{O}_{3} \cdot 5 \mathrm{H}_{2} \mathrm{O}$. TG and DSC were characterized by using a SETARAM LABSYS thermal analyzer under an $\mathrm{N}_{2}$ atmosphere with a heating rate of $10 \mathrm{~K} \cdot \mathrm{min}^{-1}$ from 298.15 to $823.15 \mathrm{~K}$. The TG-DSC curve in Figure 2 shows that the weight loss of $17.42 \%$ corresponds to the loss of five water molecules, which is in good agreement with the calculated value of $17.60 \%$.

The concentration of $\mathrm{B}_{2} \mathrm{O}_{3}$ was determined by the gravimetric method with sodium hydroxide standard solution in the presence of mannitol and double indicator of methyl red and phenolphthalein, and the uncertainty of the results was less than 0.0005 in mass fraction [10]. The cesium ion content was obtained by using an inductively coupled plasma optical emission spectrometer (Prodigy, Leman Corporation, America) with a precision of \pm 0.005 in mass fraction. The $\mathrm{H}_{2} \mathrm{O}$ content was analyzed by the differential subtraction. The chemical analysis results are shown in Table 1 . The results, along with $\mathrm{X}$-ray power diffraction analysis and TG curve, show that the compound has high purity and is suitable for thermodynamic experiments.

2.3. Calorimetry and Experiment Method. The highprecision SETARAM LABSYS (France) was used for heat capacity experiment, which requires three groups of experiments, namely, blank experiment, reference experiment and sample experiment, and alumina as reference experiment. To verify the performance, the heat capacity of $\mathrm{KCl}$ was measured, and the average experimental value for five times of $0.6860 \mathrm{~J} \cdot \mathrm{g}^{-1} \cdot \mathrm{K}^{-1}$ was in accordance with $0.6879 \mathrm{~J} \cdot \mathrm{g}^{-1} \cdot \mathrm{K}^{-1}$ reported in the literature [11], for which the deviation was 0.0028 . The heat capacity of sample was carried out in the range 303 to $349 \mathrm{~K}$ with a heating rate of $1 \mathrm{~K} / \mathrm{min}$, putting about $250 \mathrm{mg}$ of samples in the crucible weighted with an accuracy of $0.00001 \mathrm{~g}$, and the flow rate of $\mathrm{N}_{2}$ was $20 \mathrm{~mL} / \mathrm{min}$.

\section{Results and Discussion}

3.1. Heat Capacity. The heat capacity of sample was measured in the range $303 \mathrm{~K}$ to $349 \mathrm{~K}$ with a heating rate of $1 \mathrm{~K} / \mathrm{min}$ using the calorimeter with the standard uncertainty $0.05 \mathrm{~J} \cdot \mathrm{mol}^{-1} \cdot \mathrm{K}^{-1}$. The resulting molar heat capacity of $\mathrm{Cs}_{2} \mathrm{O} \cdot 2 \mathrm{~B}_{2} \mathrm{O}_{3} \cdot 5 \mathrm{H}_{2} \mathrm{O}$ is listed in Table 2 and shown in Figure 3. It can be seen from Figure 3 that the specific heat capacity gradually increases with the increase of temperature, increases slowly from 303 to $330 \mathrm{~K}$, and increases fast after $330 \mathrm{~K}$. No phase change was observed within the temperature range of the experiment and no other thermal abnormalities occurred.

For the sake of observing the heat capacity data and getting a heat capacity at a temperature quickly, the molar heat capacity of $\mathrm{Cs}_{2} \mathrm{O} \cdot 2 \mathrm{~B}_{2} \mathrm{O}_{3} \cdot 5 \mathrm{H}_{2} \mathrm{O}$ obtained from the experiment was fitted, which can be expressed in the following polynomial equation (1) with the correlation coefficient $r=0.9987$ and be drawn in Figure 3 . 


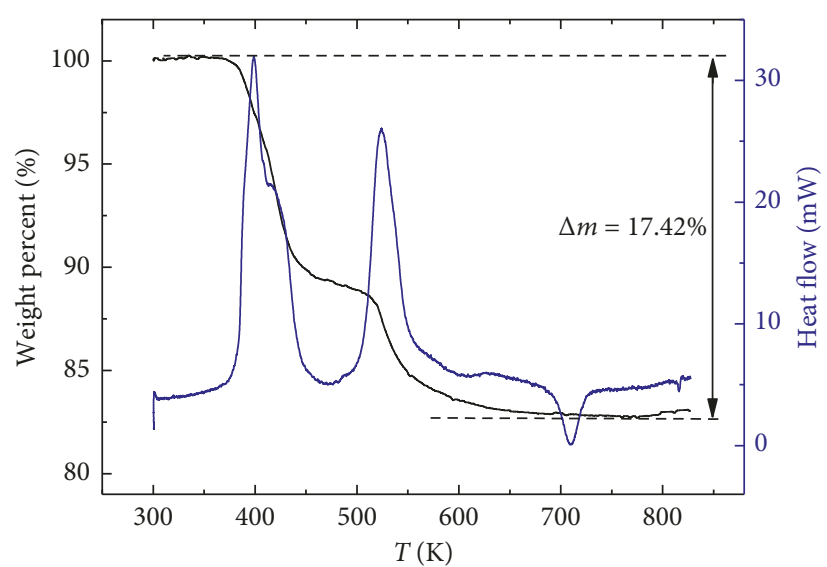

Figure 2: The TG curve of $\mathrm{Cs}_{2} \mathrm{O} \cdot 2 \mathrm{~B}_{2} \mathrm{O}_{3} \cdot 5 \mathrm{H}_{2} \mathrm{O}$.

TABLE 1: Chemical analytical results of $\mathrm{Cs}_{2} \mathrm{O} \cdot 2 \mathrm{~B}_{2} \mathrm{O}_{3} \cdot 5 \mathrm{H}_{2} \mathrm{O}$ in mass fraction ${ }^{\mathrm{a}}$.

\begin{tabular}{lcccc}
\hline & $\mathrm{Cs}_{2} \mathrm{O}$ & $\mathrm{B}_{2} \mathrm{O}_{3}$ & $\mathrm{H}_{2} \mathrm{O}$ & $n\left(\mathrm{Cs}_{2} \mathrm{O}: \mathrm{B}_{2} \mathrm{O}_{3}: \mathrm{H}_{2} \mathrm{O}\right)$ \\
\hline Experimental & 0.5533 & 0.2724 & 0.1742 & $1.00: 1.99: 4.93$ \\
Theoretical & 0.5515 & 0.2724 & 0.1761 & $1.00: 2.00: 5.00$ \\
\hline
\end{tabular}

${ }^{\mathrm{a}}$ Standard uncertainties $u$ are $u\left(\mathrm{Cs}_{2} \mathrm{O}\right)=0.0053, u\left(\mathrm{~B}_{2} \mathrm{O}_{3}\right)=0.0005$, and $u\left(\mathrm{H}_{2} \mathrm{O}\right)=0.0055$ in mass fraction.

TABLE 2: Molar heat capacity of $\mathrm{Cs}_{2} \mathrm{O} \cdot 2 \mathrm{~B}_{2} \mathrm{O}_{3} \cdot 5 \mathrm{H}_{2} \mathrm{O}$ (molecular mass $(M)=511.127 \mathrm{~g} \cdot \mathrm{mol}^{-1}$ ).

\begin{tabular}{|c|c|c|c|c|c|}
\hline$T / \mathrm{K}^{\mathrm{a}}$ & $C_{\mathrm{p}, \mathrm{m}} \mathrm{J} \cdot \mathrm{mol}^{-1} \cdot \mathrm{K}^{-1}$ & $T / \mathrm{K}$ & $C_{\mathrm{p}, \mathrm{m}} \mathrm{J} \cdot \mathrm{mol}^{-1} \cdot \mathrm{K}^{-1}$ & $T / \mathrm{K}$ & $C_{\mathrm{p}, \mathrm{m}} \mathrm{J} \cdot \mathrm{mol}^{-1} \cdot \mathrm{K}^{-1}$ \\
\hline 303.33 & 570.00 & 319.35 & 581.92 & 335.24 & 617.95 \\
\hline 304.18 & 570.56 & 320.20 & 583.56 & 336.2 & 621.95 \\
\hline 305.19 & 570.62 & 321.23 & 585.56 & 337.8 & 624.74 \\
\hline 306.28 & 571.10 & 322.32 & 586.09 & 338.35 & 627.63 \\
\hline 307.37 & 571.23 & 323.15 & 587.36 & 339.35 & 629.92 \\
\hline 308.49 & 571.49 & 324.24 & 589.06 & 340.31 & 631.70 \\
\hline 309.34 & 572.79 & 325.24 & 591.47 & 341.42 & 635.84 \\
\hline 310.26 & 572.65 & 326.19 & 593.77 & 342.4 & 637.49 \\
\hline 311.19 & 572.73 & 327.20 & 596.56 & 343.23 & 640.9 \\
\hline 312.29 & 573.54 & 328.28 & 599.75 & 344.32 & 644.88 \\
\hline 313.18 & 574.82 & 329.19 & 602.72 & 345.58 & 652.60 \\
\hline 314.19 & 575.47 & 330.27 & 605.53 & 346.27 & 656.45 \\
\hline 315.26 & 576.57 & 331.18 & 607.64 & 347.28 & 662.18 \\
\hline 316.32 & 577.17 & 332.19 & 611.02 & 348.55 & 669.30 \\
\hline 317.29 & 578.53 & 333.17 & 612.41 & & \\
\hline 318.36 & 579.41 & 334.33 & 614.99 & & \\
\hline
\end{tabular}

${ }^{a}$ Uncertainty of temperature $u(T)=0.01 \mathrm{~K}$ and the molar heat capacity uncertainty $u\left(C_{\mathrm{p}, \mathrm{m}}\right)=0.05 \mathrm{~J} \cdot \mathrm{mol}^{-1} \cdot \mathrm{K}^{-1}$.

$$
\begin{aligned}
C_{\mathrm{p}, \mathrm{m}}\left(\mathrm{J} \cdot \mathrm{mol}^{-1} \cdot \mathrm{K}^{-1}\right)= & 593.85705 \\
& +48.0694 \frac{\left[T-\left(T_{\max }+T_{\min }\right) / 2\right]}{\left[\left(T_{\max }-T_{\min }\right) / 2\right]} \\
& +24.86395\left\{\frac{\left[T-\left(T_{\max }+T_{\min }\right) / 2\right]}{\left[\left(T_{\max }-T_{\min }\right) / 2\right]}\right\}^{2} \\
& +0.53077\left\{\frac{\left[T-\left(T_{\max }+T_{\min }\right) / 2\right]}{\left[\left(T_{\max }-T_{\min }\right) / 2\right]}\right\}^{3},
\end{aligned}
$$

where $\mathrm{C}_{\mathrm{p}, \mathrm{m}}$ is the molar heat capacity of $\mathrm{Cs}_{2} \mathrm{O} \cdot 2 \mathrm{~B}_{2} \mathrm{O}_{3} \cdot 5 \mathrm{H}_{2} \mathrm{O}$, $T$ is the absolute temperature in kelvin, and $T_{\max }$ and $T_{\min }$ express the maximum and minimum temperatures, i.e., 349 and 303, respectively. The molar heat capacity of $\mathrm{Cs}_{2} \mathrm{O} \cdot 2 \mathrm{~B}_{2} \mathrm{O}_{3} \cdot 5 \mathrm{H}_{2} \mathrm{O}$ at $303 \mathrm{~K}$ can be calculated as $370 \mathrm{~J} \cdot \mathrm{mol}^{-1} \cdot \mathrm{K}^{-1}$ according to the above equation, and all deviations between the experimental values, $C_{p \text {,exp }}$, and the fitted values, $C_{p \text {,fit }}$, were within 0.005 , as shown in Figure 4.

3.2. Enthalpy, Entropy, and Gibbs Free Energy. The thermodynamic functions of $\mathrm{Cs}_{2} \mathrm{O} \cdot 2 \mathrm{~B}_{2} \mathrm{O}_{3} \cdot 5 \mathrm{H}_{2} \mathrm{O}$ were obtained by the following thermodynamic equations: 


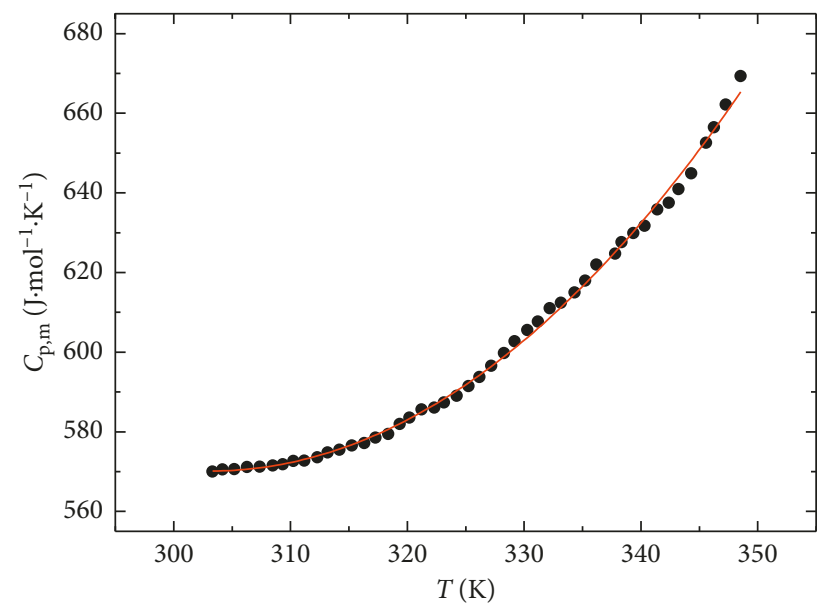

- $C_{\mathrm{p}, \exp }$

FIGURE 3: Experimental and fitting molar heat capacity of $\mathrm{Cs}_{2} \mathrm{O} \cdot 2 \mathrm{~B}_{2} \mathrm{O}_{3} \cdot 5 \mathrm{H}_{2} \mathrm{O}$ in the range of 303 to $349 \mathrm{~K}$.

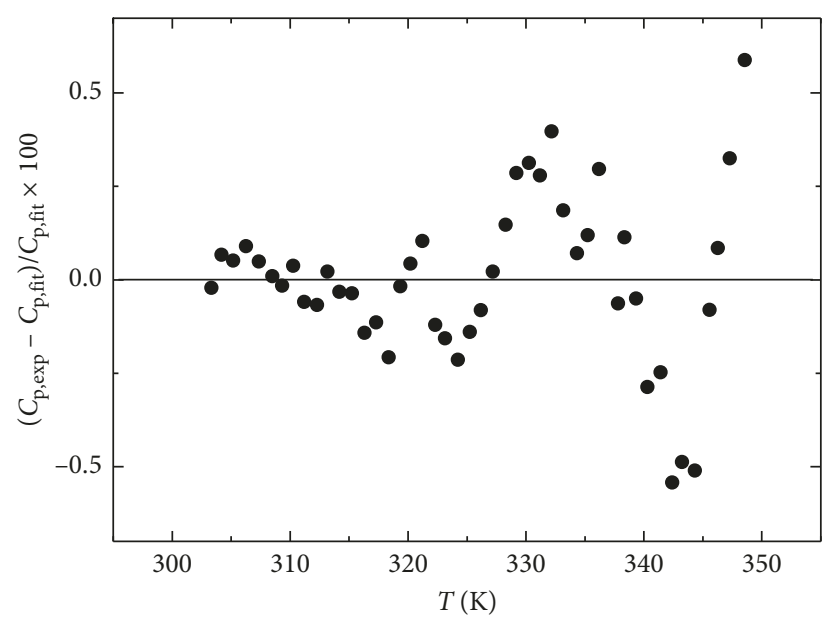

FIGURE 4: The deviations of the experimental and fitting values.

TABLE 3: Molar heat capacity and thermodynamic functions of $\mathrm{Cs}_{2} \mathrm{O} \cdot 2 \mathrm{~B}_{2} \mathrm{O}_{3} \cdot 5 \mathrm{H}_{2} \mathrm{O}$.

\begin{tabular}{lcccc}
\hline$T / \mathrm{K}$ & $C_{\mathrm{p}, \mathrm{m}} \mathrm{J} \cdot \mathrm{mol}^{-1} \cdot \mathrm{K}^{-1}$ & $H_{T}-H_{303} \mathrm{~kJ} \cdot \mathrm{mol}^{-1}$ & $S_{T}-S_{303} \mathrm{~J} \cdot \mathrm{mol}^{-1} \cdot \mathrm{K}^{-1}$ & $G_{T}-G_{303} \mathrm{~kJ} \cdot \mathrm{mol}^{-1}$ \\
\hline 303 & 570.12 & 0 & 0 & 0 \\
305 & 570.29 & 6.763 & -6.940 & 8.880 \\
307 & 570.82 & 13.468 & -14.009 & 26.769 \\
309 & 571.69 & 20.114 & -21.203 & 35.572 \\
311 & 572.93 & 26.703 & -28.520 & 44.487 \\
313 & 574.53 & 33.232 & -35.957 & 53.410 \\
315 & 576.49 & 39.704 & -43.512 & 62.342 \\
317 & 578.82 & 46.117 & -51.182 & 71.283 \\
319 & 581.51 & 52.473 & -58.965 & 80.232 \\
321 & 584.58 & 58.770 & -66.859 & 89.190 \\
323 & 588.01 & 65.010 & -74.861 & 98.157 \\
325 & 591.81 & 71.192 & -82.969 & 107.133 \\
327 & 595.99 & 77.317 & -91.181 & 116.117 \\
329 & 600.55 & 83.384 & -99.493 & 125.110 \\
331 & 605.48 & 89.394 & -107.905 & 134.112 \\
\hline 33 & 610.80 & 95.346 & -116.414 & \\
\hline
\end{tabular}


TABLE 3: Continued.

\begin{tabular}{lcccc}
\hline$T / \mathrm{K}$ & $C_{\mathrm{p}, \mathrm{m}} \mathrm{J} \cdot \mathrm{mol}^{-1} \cdot \mathrm{K}^{-1}$ & $H_{T}-H_{303} \mathrm{~kJ} \cdot \mathrm{mol}^{-1}$ & $S_{T}-S_{303} \mathrm{~J} \cdot \mathrm{mol}^{-1} \cdot \mathrm{K}^{-1}$ & $G_{T}-G_{303} \mathrm{~kJ} \cdot \mathrm{mol}^{-1}$ \\
\hline 335 & 616.50 & 101.242 & -125.017 & 143.122 \\
337 & 622.59 & 107.080 & -133.713 & 152.142 \\
339 & 629.07 & 112.862 & -142.500 & 161.169 \\
341 & 635.93 & 118.587 & -151.374 & 170.206 \\
343 & 643.18 & 124.255 & -160.335 & 179.250 \\
345 & 650.83 & 129.868 & -169.380 & 188.304 \\
347 & 658.88 & 135.424 & -178.507 & 197.366 \\
\hline
\end{tabular}

$$
\begin{aligned}
H_{T}-H_{303} & =\int_{303}^{T} C_{\mathrm{p}, \mathrm{m}} d T \\
S_{T}-S_{303} & =\int_{303}^{T}\left[\frac{C_{\mathrm{p}, \mathrm{m}}}{T}\right] d T \\
G_{T}-G_{303} & =\int_{303}^{T} C_{\mathrm{p}, \mathrm{m}} d T-T \int_{303}^{T}\left[\frac{C_{\mathrm{p}, \mathrm{m}}}{T}\right] d T .
\end{aligned}
$$

The values of the molar heat capacity and thermodynamic functions of $\left(H_{T}-H_{303}\right),\left(S_{T}-S_{303}\right)$, and $\left(G_{T}-G_{303}\right)$ are listed in Table 3 at an interval of $2 \mathrm{~K}$. As can be seen from Table 3, the molar heat capacity and thermodynamic functions of $\left(H_{T}-H_{303}\right)$ and $\left(G_{T}-G_{303}\right)$ are increased with the rise of temperature, but the entropy $\left(S_{T}-S_{303}\right)$ is decreased.

\section{Conclusions}

The heat capacity of cesium tetraborate pentahydrate was measured ranging from 303 to $349 \mathrm{~K}$ with a heating rate of $1 \mathrm{~K} / \mathrm{min}$ using the high-precision calorimeter without phase transition and thermal anomaly, which were fitted and shown as $C_{\mathrm{p}, \mathrm{m}}\left(\mathrm{J} \cdot \mathrm{mol}^{-1} \cdot \mathrm{K}^{-1}\right)=593.85705+48.0694\left[T-\left(T_{\max }+T_{\min }\right) / 2\right] /$ $\left.\left(T_{\max }-T_{\min }\right) / 2\right]+24.86395\left[\left(T-\left(T_{\max }+T_{\min }\right) / 2\right) /\left(T_{\max }-T_{\min }\right) /\right.$ $2]^{2}+0.53077\left[\left(T-\left(T_{\max }+T_{\min }\right) / 2\right) /\left(T_{\max }-T_{\min }\right) / 2\right]^{3}$. The molar heat capacity and thermodynamic functions of $\left(H_{T}-H_{303}\right)$, $\left(S_{T}-S_{303}\right)$, and $\left(G_{T}-G_{303}\right)$ are obtained with the temperature of $2 \mathrm{~K}$ interval.

\section{Data Availability}

The data used to support the findings of this study are available from the corresponding author upon request.

\section{Conflicts of Interest}

The authors declare that they have no conflicts of interest.

\section{Acknowledgments}

Financial supports from the National Natural Science Foundation of China (U1607123 and 21773170), the Key Projects of Natural Science Foundation of Tianjin (18JCZDJC10040), and the Yangtze Scholars and Innovative Research Team in Chinese University (IRT_17R81) are acknowledged.

\section{References}

[1] P. H. Sun, C. H. Fang, Y. Fang et al., "Physicochemical properties and Raman spectra of cesium tetraborate solution," Journal of Salt Lake Research, vol. 24, no. 1, pp. 29-37, 2016.

[2] P. H. Sun, Structure of Aqueous Cesium Borate Solution, University of Chinese Academy of Science, Beijing, China, 2016.

[3] W. J. Song, S. Z. Yang, and B. Z. Mu, "Determination methods for rubidium and cesium in salt lake brine," Inorganic Chemicals Industry, vol. 46, no. 11, pp. 55-58, 2014.

[4] H. Lu, D. C. Feng, and J. Y. Yang, "Comparison of differential scanning calorimetry and modulated differential scanning calorimetry in measurement of specific heat capacities," Analytical Instrument, vol. 3, pp. 70-74, 2011.

[5] Z. Liu, S. Li, and M. Hu, "Thermodynamic properties of $\mathrm{Cs}_{2} \mathrm{~B}_{4} \mathrm{O}_{5}(\mathrm{OH})_{4} \cdot 3 \mathrm{H}_{2} \mathrm{O}$," Journal of Chemical Thermodynamics, vol. 37, no. 9, pp. 1003-1006, 2005.

[6] M. Touboul, N. Penin, and G. Nowogrocki, "Crystal structure and thermal behavior of $\mathrm{Cs}_{2} \mathrm{~B}_{4} \mathrm{O}_{5}(\mathrm{OH})_{4} 3 \mathrm{H}_{2} \mathrm{O}$," Journal of Solid State Chemistry, vol. 143, no. 2, pp. 260-265, 1999.

[7] Z.-H. Zhang, G.-Y. Yin, Z.-C. Tan, Y. Yao, and L.-X. Sun, "Heat capacities and thermodynamic properties of a $\mathrm{H}_{2} \mathrm{O}+$ $\mathrm{Li}_{2} \mathrm{~B}_{4} \mathrm{O}_{7}$ solution in the temperature range from 80 to $356 \mathrm{~K}$," Journal of Solution Chemistry, vol. 35, no. 10, pp. 1347-1355, 2006.

[8] W. Cui, L. Li, Y. Guo, S. Zhang, and T. Deng, "Heat capacity and thermodynamic property of lithium pentaborate pentahydrate," Journal of Chemistry, vol. 2018, no. 6, Article ID 7962739, 4 pages, 2018.

[9] Z. H. Liu, B. Gao, M. C. Hu et al., "FT-IR and Raman spectroscopic analysis of hydrated cesium borates and their saturated aqueous solution," Spectrochimica Acta Part A: Molecular and Biomolecular Spectroscopy, vol. 59, no. 12, pp. 2741-2745, 2003.

[10] Qinghai Institute of Salt Lakes of CAS, Analytical Methods of Brines and Salts, Chinese Science Press, Beijing, China, 2nd edition, 1988.

[11] J. G. Speight, Lange's Handbook of Chemistry, McGraw-Hill, New York, NY, USA, 16th edition, 2005. 

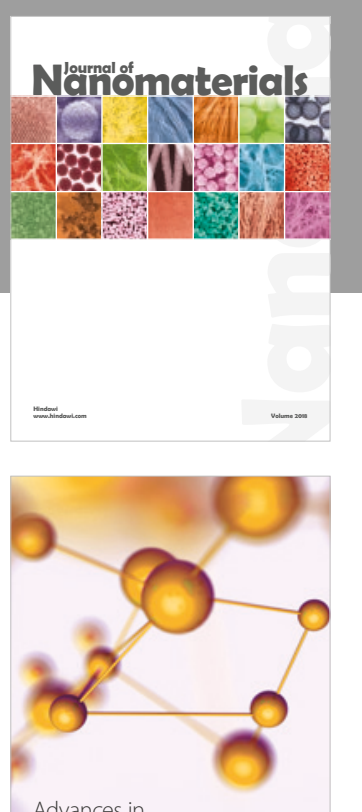

Physical Chemistry
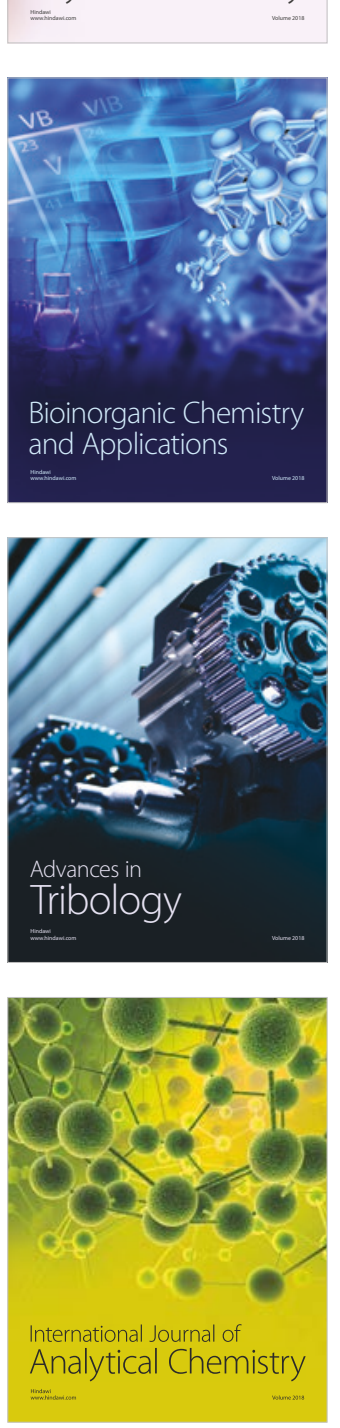

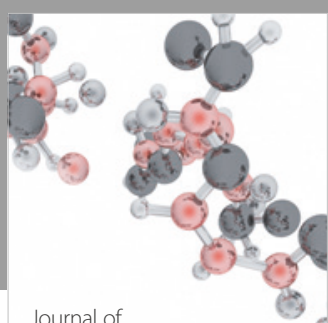

Analytical Methods

in Chemistry

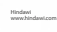

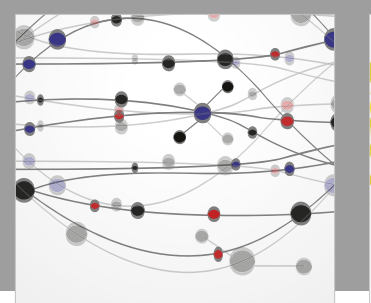

The Scientific World Journal

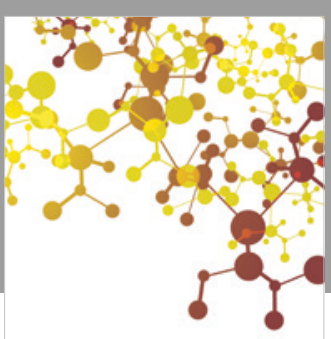

Journal of

Applied Chemistry
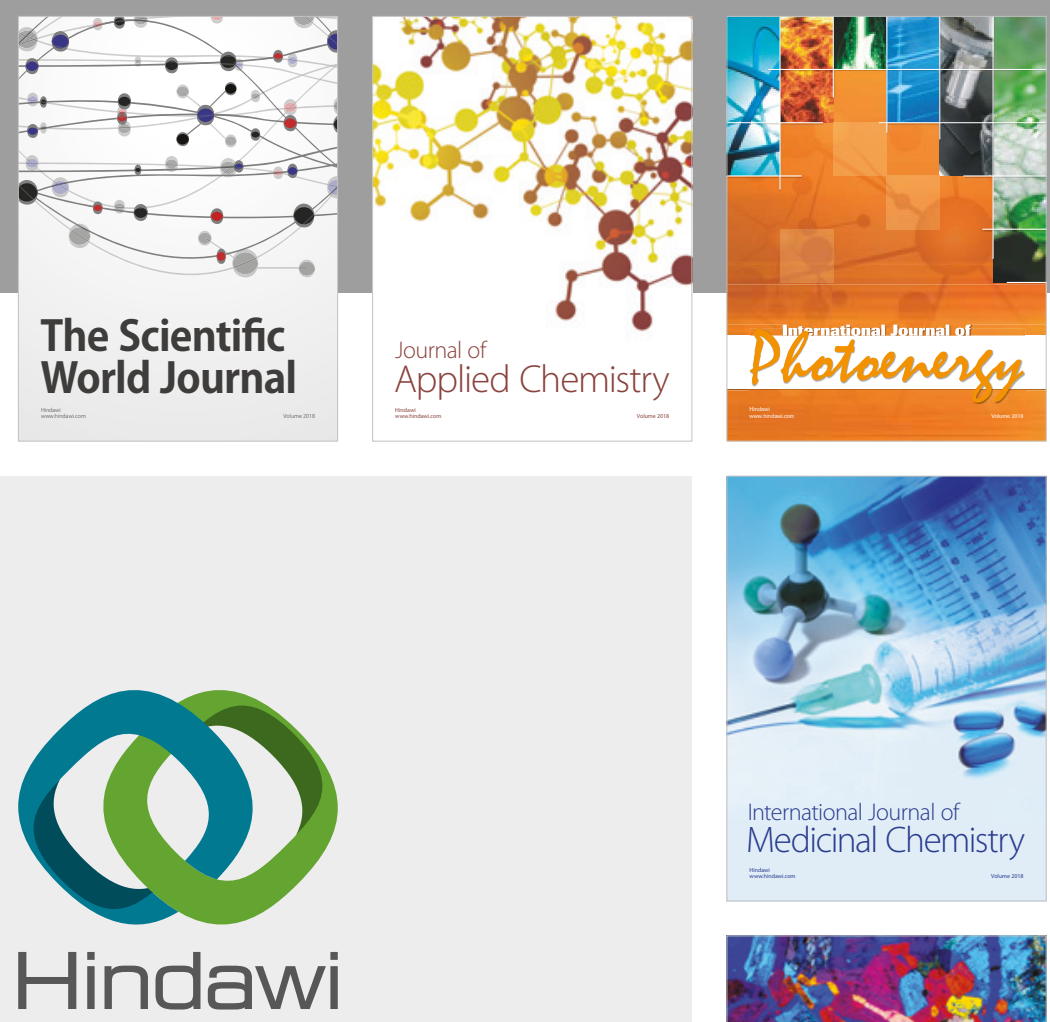

Submit your manuscripts at

www.hindawi.com
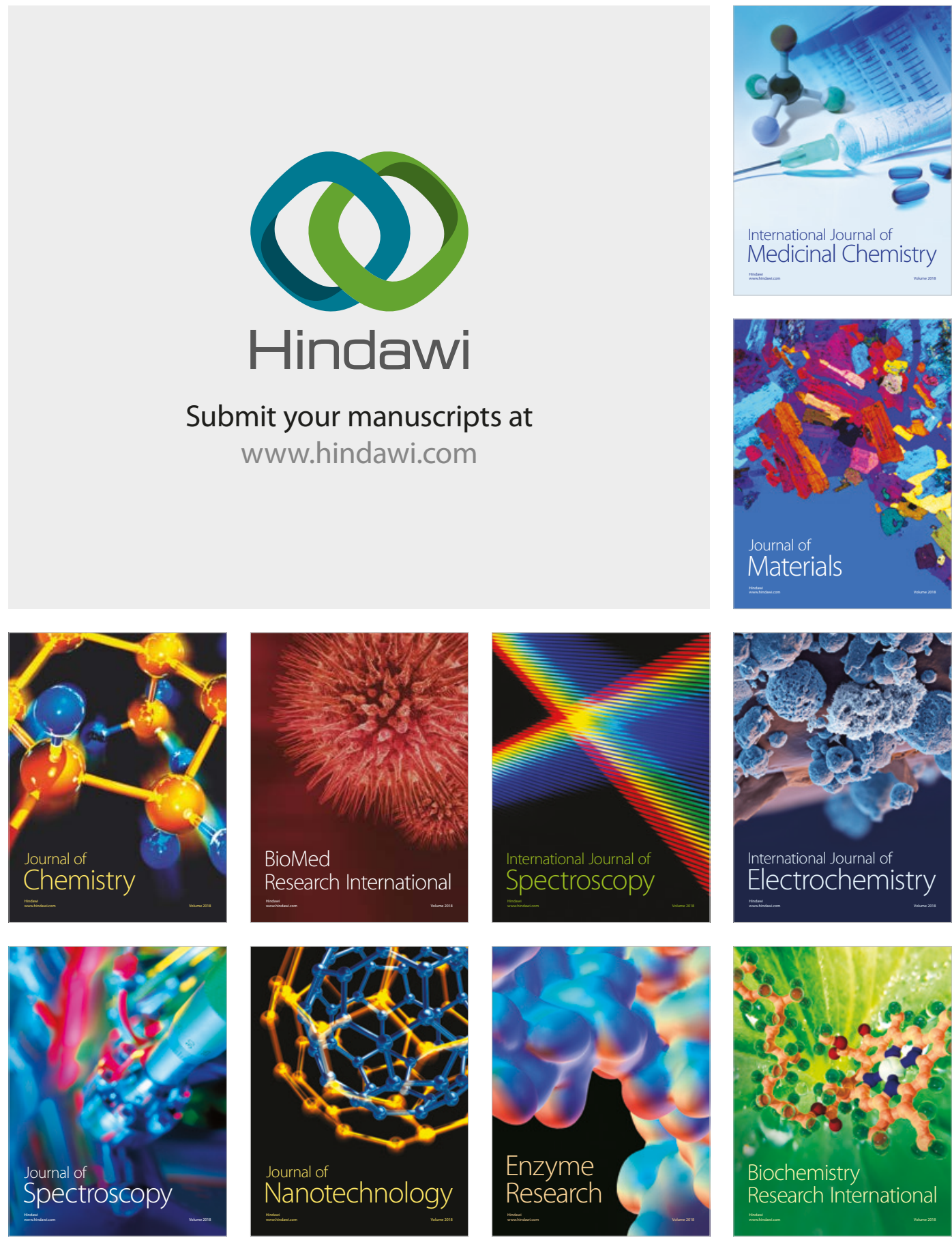
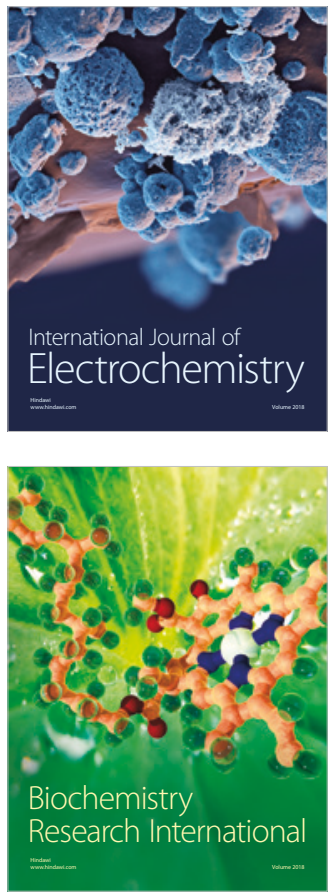